\title{
Achievement Motivation, Locus of Control and Study Habits as Predictors of Mathematics Achievement of New College Students
}

\author{
Estelita Arellano Villa ${ }^{1 *}$ (D), Mildred Arellano Sebastian ${ }^{1}$ (D)
}

${ }^{1}$ Cavite State University - Tanza Campus, PHILIPPINES
${ }^{\star}$ Corresponding Author: estelita.villa@cvsu.edu.ph

Citation: Villa, E. A., \& Sebastian, M. A. (2021). Achievement Motivation, Locus of Control and Study Habits as Predictors of Mathematics Achievement of New College Students. International Electronic Journal of mathematics Education, $16(3)$, em0661. https://doi.org/10.29333/iejme/11297

\section{ARTICLE INFO}

Received: 5 Apr. 2021

Accepted: 14 Sep. 2021

\begin{abstract}
Several researchers have investigated different factors which are found responsible for students' mathematics achievement. This study examined achievement motivation, locus of control and study habits as predictors of mathematics achievement of freshman students taking non-board examination programs at a certain state university in Southern Luzon, Philippines. In this descriptive-correlational research design, purposive sampling technique was used to select 258 participants enrolled in the subject mathematics in the Modern World. Four sets of research instruments were used for the data collection: namely, mathematics Achievement Motivation Scale, Locus of Control Scale, mathematics Study Habits Inventory and the teacher-made mathematics Achievement Test. The results showed that most students have average achievement motivation, internal locus of control, desirable study habits and average mathematics achievement. The results also revealed that there was a significant relationship between achievement motivation and mathematics achievement and achievement motivation was found to be the only predictor of mathematics achievement. This indicates that achievement motivation is effective in enhancing mathematics achievement. Students' achievement motivation will increase to high level if given the right remediation. Hence, high achievement motivation can predict high mathematics achievement.
\end{abstract}

Keywords: mathematics achievement, achievement motivation, locus of control, internal locus of control, external locus of control, study habits

\section{INTRODUCTION}

Having a solid foundation of mathematics subject is having the ability to think critically and solve problems creatively; and this ability is necessary for success in life. However, learning mathematics is not easy for most Filipino students as they were found to have difficulty in understanding mathematics lessons that require higher order thinking skills (Patena \& Dinglasan, 2013). Even college students are not excluded from the problem in learning and mastering mathematics and this is visible in the students' low performance in mathematics test (Andaya, 2014). Obiero (2018) observed that poor mathematics achievement has been a concern worldwide despite the actual studies that have been done on certain factors which have been recognized as possible contributors to mathematics achievement. Poor mathematics achievement is a learning disability and major cause of failure in school (Dela Cruz, 2018). So, it is necessary to identify the factors that may affect mathematics achievement of the students for the teachers and the administrators to find solution for improvement.

Various researchers have explored many factors which are found responsible for success or failure in mathematics and some of these include achievement motivation, locus of control and study habits. On one hand, achievement motivation plays a very important role in the teaching and learning process (Hasan \& Sarkar, 2018) as it is described as a student's inner drive to achieve and if that student lacks that desire to achieve, the academic performance will be affected. On the other hand, locus of control plays an important role in learning motivation and in the development of a person, which could affect the achievement of students (Nongtdu \& Bhutia, 2017). According to Choudhury and Borooah (2017), locus of control is a student's personality and his belief in the causes of his success or failure in academics and can be classified as either internal or external. Students with internal locus of control believe that the causes of their success or failure is a result of their own efforts and abilities; while students with external locus of control believe that factors like luck, task difficulty or other people's action often result to their success or failure (Gujjar \& Aijaz, 2014). Atetwe et al. (2018) found out that an internal locus of control predicts high mathematics achievement.

Furthermore, students' study habits play a vital role in reflecting the standard of education and the students' mathematics achievement (Odiri, 2015). According to Sharma and Vyas (2016), study habits refer to the way of exercising students' abilities in 
the process of learning. The general belief is that students who exercise good study habits are expected to excel than those with bad study habits (Arora, 2016). Improving achievement motivation and study habits (Daniel, 2015) and internal locus of control (Atetwe et al., 2018) among students may enhance their mathematics achievement. Thus, it is important to determine whether these variables could predict students' mathematics achievement so that necessary intervention programs can be recommended.

As such, the researcher attempted to determine whether achievement motivation, locus of control and study habits are predictors of mathematics achievement of college students enrolled in non-board examination programs under tourism and hospitality management and business management taking the subject mathematics in the Modern World during the first semester of the academic year 2019-2020 at a certain state university in Southern Luzon, Philippines. To achieve this, the following research questions were set:

1. What is the profile of the students in terms of achievement motivation, locus of control, study habits and mathematics achievement?

2. Is there a significant relationship between student's mathematics achievement and achievement motivation, locus of control, and study habits?

3. To what extent do students' achievement motivation, locus of control and study habits predict their mathematics achievement?

\section{LITERATURE REVIEW}

The importance of achievement motivation, locus of control and study habits in the teaching and learning process is emphasized in most studies. Each of these factors can predict mathematics achievement as seen in the results of the studies conducted about achievement motivation, locus of control and study habits. Students were found to possess high level of achievement motivation, internal locus of control and good study habits.

\section{Achievement Motivation}

In a study of the way how people satisfy their needs, American psychologist David McClelland concluded that people have motivating drivers that are directly linked to their needs regardless of age, gender, culture and race (Mulder 2015). One of these, based on McClelland's Human Motivation Theory, is the need for achievement or achievement motivation. Achievement motivation is defined by McClelland as the positive and negative effects that arose in situations involving certain standards of excellence where performance in such situations can be assessed as success or failure (Daniel, 2015). It is an inner drive that motivates the students to achieve a particular goal (Kaur, 2017). When students are motivated to perform competently on academic tasks, they will learn according to their abilities; hence, learning of the students is maximized when their achievement motivation is enhanced (Yazdani \& Godbole, 2014).

\section{Locus of Control}

The concept of locus of control was formulated by psychologist Julian B. Rotter in 1954 and referred it as a dimension of personality which helps explain one's traits and behaviors (Choudhury \& Borooah, 2017). Locus of control is a variable which refers to an individual's belief about the causes of the good or bad result in his or her life, either in general or in specific area such as in academics (Kumar \& Asha, 2017). According to Curtis and Trice (2013), Rotter defined locus of control as a set of stable beliefs that predict performance in achievement contexts and can be conceptualized as either internal or external (Mathur, 2014). A person with internal locus of control believe that their ability and effort are essential for achievement and can be used to assess the causes of success or failure of individuals; while those with an external locus of control view luck, chance, the influence of powerful others (such as teachers), and the difficulty of the task as the primary factors determining success or failure. Ashton D. Trice developed the Academic Locus of Control Scale in 1985 specifically designed for college students and conducted a study together with Nicholas A. Curtis regarding its revisions in 2013. In their study, four factors were found within the Academic Locus of Control namely, hopelessness, distractibility, poor student attitude and impaired planning. It was suggested that seven items from the original scale which did not load on these four factors should be removed.

\section{Study Habits}

Study habits refer to the way of studying in whatever manner, whether systematic or unsystematic, efficient or otherwise (Sharma \& Vyas, 2016). Student's study habits differ from one another. Some study habits are considered to be more desirable than others from the view of academic achievement (Arora, 2016). Although variations exist among the students, there are some good study habits that will lead to academic achievement. Good study habits are the practices that could improve students' concentration, remembering, organizing time, studying, listening and taking notes, taking tests and motivation (Llavore et al., (2015). Prof. M.N. Palsane and Sadhna Sharma constructed a study habit inventory composed of eight different domains. The eight domains of the study habits include (1) time management, (2) physical status, (3) note-taking, (4) testing strategies, (5) learning motivation, (6) reading ability, (7) memory and (8) health. This was the basis of the adaptation of the Study Habits questionnaire.

\section{Mathematics Achievement}

Academic achievement is defined as a measure of knowledge, understanding or skills in a specific subject or a group of subjects and can be described as a successful accomplishment in a particular subject area (Verma, 2016). Mathematics is an academic discipline that has a very important application in science and technology (Singh, 2015), and Charles-Ogan and Alamina (2014) 
noted that having a strong background in mathematics is crucial for many careers and job opportunities in today's technological society. However, despite its usefulness and importance, it is still perceived by the students as difficult, boring, abstract, and that achievement in mathematics requires a special ability (Daniel, 2015). Dela Cruz (2018) stated that poor academic achievement in mathematics is a learning disability for Filipinos and a major cause of failure in academics. Thus, it is necessary to observe the teaching and learning process in mathematics so that this important subject is fully presented to the students and that they may have a great interest and more achievements in the subject (Singh, 2015).

\section{Achievement Motivation and Mathematics Achievement}

Sahayarani and Stanley (2017) found out that the level of achievement motivation of the students was above average and showed a high positive correlation with achievement in mathematics. In addition, Sarangi (2015) determined the relationship between achievement motivation and academic achievement on the basis of community, locale and sex. The study revealed a significant relationship between achievement motivation and academic achievement in the case of non-tribal, female, and rural and urban students while a no significant relationship existed between tribal and male students. In contrast, the study of Hasan and Sarkar (2018) showed a non-significant correlation between achievement motivation and academic achievement of the students. Furthermore, Obiero (2018) found a positive but weak and none significant relationship between achievement motivation and mathematics achievement of the students.

\section{Locus of Control and Mathematics Achievement}

Several factors may contribute to academic achievement, but locus of control is one variable that has been overlooked and can be studied and reviewed as an important indicator in predicting academic success and failure of the students (Anakwe, 2018). Gujjar and Aijaz (2014) stated that locus is a personal belief about who can control the consequences of a student's action, referring to success and failure in academics. Mathur (2014) revealed that college students with an internal locus of control can be expected to perform better in their academics and also have a positive attitude towards life whereas the ones with an external locus of control are not expected to perform well as the previous one. Raheem and Abdulkadir (2018) found that if a person with an internal locus of control does not perform well in a test, he would blame it on lack of preparedness on his part and if he performed well in a test, he would attribute this to his ability to study. On the other hand, if a person with a high external locus of control does poorly in a test, he might attribute this to the difficulty of the test questions and if he performed well in it, he might think the teacher was lenient or that he was lucky. Since the student is the one responsible for the consequence of his or her success or failure in academics, Nongtdu and Bhutia (2017) concluded that internal locus of control should be encouraged among students so they would work harder for their own progress.

Choudhury and Borooah (2017) found no significant correlation between external locus of control and academic achievement, which indicates that external locus of control did not influence the academic achievement of the students. On the other hand, Atetwe et al. (2018) found that there was statistically significant correlation between internal locus of control and mathematics achievement and that high level of internal locus of control was associated with high mathematics achievement. Atetwe et al. also added that a variety of learning strategies should be used that would encourage students to improve their internal locus of control and make them realized that they have more control over their mathematics achievement and this would enable the students to take responsibility of their learning and have a possible high achievement in mathematics (2018).

\section{Study Habits and Mathematics Achievement}

Moreover, Sharma and Vyas (2016) stated that good study habits will result in good academic achievement whereas bad study habit will result in a poor academic achievement. Specifically, good study habits lead to better mathematics achievement and lack of good study habits results in poor mathematics achievement (Odiri, 2015). Hence, teachers should provide ways in improving the student's study habits by capitalizing on the student's strengths and work on their weaknesses by preparing activities that match their cognitive abilities and time for independent learning must be used properly to increase mathematics achievement (Dela Cruz, 2018). However, Arora (2016) revealed that proper study habits should be taught at the early stage of the students and efforts should be made both by parents and the school authorities to provide suitable environment to develop good study habits among the students to stop academic failure. Therefore, it can be said that learning how to study or to develop good study habits is a lifelong process, and one should be ready to modify one's method of study according to the need of time (Lawrence, 2014).

\section{Achievement Motivation, Study Habits and Mathematics Achievement}

Knowing the possible influences of many factors in the academic achievement of the students yet hard to identify and analyze all factors, Suresh (2015) conducted a study to find its influences to selected factors like achievement motivation and study habits of the students. It was found out that academic achievement was highly influenced by achievement motivation compared to study habits. Particularly, achievement motivation made the most significant contribution to the prediction of mathematics achievement followed by study habits (Daniel, 2015). Yazdani and Godbole (2014) concluded in their study that achievement motivation and study habits and its eight domains of time management, physical status, study aids/note-taking, learning motivation, testing strategies, reading ability, memory and health are said to be effective in helping the students gain better performance and academic achievement. Thus, Kaur (2017) stated that academic achievement can be improved by having proper achievement motivation and improving good study habits. 
Table 1. Students' profile of achievement motivation, locus of control, study habits and mathematics achievement

\begin{tabular}{|c|c|c|c|}
\hline \multicolumn{2}{|c|}{ Variables } & \multirow{2}{*}{$\begin{array}{c}\text { Frequency }(\mathbf{N}=\mathbf{2 5 8}) \\
59\end{array}$} & \multirow{2}{*}{$\begin{array}{c}\text { Percentage } \\
22.87\end{array}$} \\
\hline & Low & & \\
\hline Achievement Motivation & Average & 137 & 53.10 \\
\hline & High & 62 & 24.03 \\
\hline \multirow{2}{*}{ Locus of Control } & External & 83 & 32.17 \\
\hline & Internal & 175 & 67.83 \\
\hline \multirow{2}{*}{ Study Habits } & Desirable & 172 & 66.67 \\
\hline & Undesirable & 86 & 33.33 \\
\hline \multirow{3}{*}{ Mathematics Achievement } & High & 39 & 15.12 \\
\hline & Average & 183 & 70.93 \\
\hline & Low & 36 & 13.95 \\
\hline
\end{tabular}

\section{METHODOLOGY}

A descriptive-correlational design was employed in this study. Three independent variables namely, achievement motivation, locus of control and study habits were used to determine whether they were predictors of mathematics achievement of college students taking non-board examination programs. A total of 258 students who were enrolled in Bachelor of Science in Tourism Management, Bachelor of Science in Hospitality Management and Bachelor of Science in Business Management, all of which are non-board examination programs were purposively selected to participate in the study. The participants were enrolled in the course mathematics in the Modern World during the first semester of the academic year 2019-2020 at a certain state university in Southern Luzon, Philippines.

The researcher used four (4) research instruments in collecting data for the study. First, the researcher used the mathematics Achievement Motivation Scale to measure the achievement motivation of the students. It was adapted from Achievement Motivation Scale by Prathibha Deo and Asha Mohan (2002) originally with a total item of 50 . Some of the items were modified to suit the student's achievement motivation in mathematics and 7 items were removed because they are not related to the study. The questionnaire used in this study consisted of 42 items covering description of the items such as academic motivation, need for achievement, academic challenge, achievement anxiety, importance of grades, meaningfulness of task, relevance of college to future goals, attitude towards education, work methods, attitude towards teachers, interpersonal relations, individual concern and general interests. The scale was validated by three experts in the fields of education and psychology. After validation, it was pilot-tested among 35 students who were not part of the population under study. It has a Cronbach's alpha of 0.784 which is greater than the minimum acceptable requirement of 0.70 (George \& Mallery, 2003).

The second instrument is the Locus of Control Scale, which was used to measure the locus of control of the students. This was adapted from Ashton D. Trice's Revised Academic Locus of Control Scale (2013). Some items were modified to fit the student's locus of control in mathematics. The questionnaires consisted of 21 items and each item consisted of true or false responses. It was also pilot-tested to another group of 35 students who were not part of the population under study. The computed Cronbach's alpha for the data gathered is 0.725 .

The third instrument, the mathematics Study Habits Inventory, was used to measure the study habits of the students. It was adapted from Study Habits Inventory by M. N. Palsane and Sadhna Sharma (1989), which was originally a 45-item test. There were items on study habits that were modified and others were removed because the questions were not related to the study. The final instrument consisted of 37 items which measured the students' study habits in terms of time management, physical status, study aids/note taking, motivation, testing strategies, reading ability, memory, and health and was validated by three experts in the field of education and psychology. It was also pilot-tested to another set of 35 students who were not part of the population under study. The computed Cronbach's alpha for the data is 0.705 .

Finally, a teacher-made test was constructed to determine the mathematics achievement of the students and was validated by three experts. This consisted of 40-item multiple choice type test. The coverage of the exam included topics based on the mathematics in the Modern World taken by the students. The topics included Patterns and Numbers in Nature, Mathematical Languages and Symbols, Problem Solving and Reasoning and Data Management.

Permit to conduct the study was first secured from the Office of the Administrator of the state university. After gathering the total number of first year students enrolled in non-board courses, the researcher proceeded to the distribution of the four different questionnaires. The researcher was accompanied by a psychometrician in administering the tests for two consecutive days except for mathematics Achievement Test.

\section{RESULTS}

\section{Student's Profile}

Majority of the students have average achievement motivation, internal locus of control, desirable study habits and average mathematics achievement. The results are presented in Table 1.

The average achievement motivation of the freshman students obtained was similar to the result of the studies conducted by Chetri (2014), Sarangi (2015), Roy (2015) and Rani and Reddy (2019). It indicates that with little guidance from the teacher, 
Table 2. Correlation coefficients between mathematics achievement and its predictors

\begin{tabular}{cccc}
\hline Predictor variables & Correlation coefficient & Significance level & Remarks \\
\hline Achievement Motivation & 0.205 & 0.001 & Significant Relationship \\
\hline Locus of Control & 0.025 & 0.689 & Not Significant Relationship \\
\hline Study Habits & 0.110 & 0.078 & Not Significant Relationship \\
\hline
\end{tabular}

Table 3. Model summary for the mathematics achievement

\begin{tabular}{|c|c|c|c|c|c|}
\hline \multirow{2}{*}{ Model Components } & \multicolumn{2}{|c|}{ Unstandardized Coefficients } & \multirow{2}{*}{$\begin{array}{c}\text { Standardized Coefficients } \\
\text { Beta } \\
\end{array}$} & \multirow{2}{*}{ t-test } & \multirow{2}{*}{ Sig. level } \\
\hline & B & Std. Error & & & \\
\hline (Constant) & 9.6017 & 1.8829 & & 5.099 & $6.635^{-7^{*}}$ \\
\hline Achievement Motivation & 0.0622 & 0.0185 & 0.2055 & 3.359 & $0.0009^{*}$ \\
\hline
\end{tabular}

student's achievement motivation can be improved to high level. Hence, achievement motivation of the student can greatly contribute to his or her academic performance.

First year students were found to have internal locus of control. The findings of the studies of Gujjar and Aijaz (2014), Mashayekhi et al. (2014) and Mohamed et al. (2018) were similar to this study which found that majority of the college students possessed an internal locus of control. The internal locus of control of the students is significantly associated with good academic performance while external locus of control is related to low academic performance (Khir et al., 2015). Thus, having an internal locus of control indicates that students can be expected to perform better in their academics given adequate feedbacks.

For students' study habits, the obtained desirable study habits were measured in terms of the eight domains of time management, physical status, study aids/note taking, testing strategies, learning motivation, reading ability memory and health. However, in terms of each domain, only the reading ability, memory and health gained undesirable study habits. This indicates that students did not manifest fondness in reading or may have difficulties in understanding the meaning of some words. Students also found it hard to remember the reviewed materials and experienced disappointments in the outcome of the examination.

A desirable study habit is a good study habit. Students who have good study habits are organized, keeping good notes, reading textbooks, listening in class, and coming to class every day (Verma, 2016). Charles-Ogan and Alamina (2014) also found out in their study that majority of the students have good study habits. Odiri (2015) revealed that good study habits lead to better achievement in mathematics.

As for the students' mathematics achievement, the result conforms to the statement of Kushwaha (2014) that in considering a group of students, a large number of students always appeared as average achievers while only few students are found to be high and low achievers.

\section{Significant Relationship between Mathematics Achievement and its Predictors}

Educators are increasingly recognizing the importance of improving students' mathematics achievement. With this in mind, the researcher focused on the factors which might be influential to this achievement by conducting both the bivariate correlation (Table 2) and the multiple linear regressions.

Mathematics achievement is positively influenced by a certain variable. Based on Table 6, significant correlations $(p=0.05)$ exist between the students' mathematics achievement and its predictor, achievement motivation ( $r=0.205)$. The result of this study is similar to the findings of the study of Sahayarani and Stanley (2017) which revealed that there existed a significant relationship between achievement motivation and mathematics achievement. This implies that if a student's motivation is improved, the mathematics achievement can also be improved. Once a student is motivated in reaching goals in life, he/she can achieve more success as he/she will do everything to reach this goal.

However, locus of control and study habits had no significant relationship to the students' mathematics achievement. This study contradicts the findings of the studies conducted by Atetwe et al. (2018) about locus of control and Charles-Ogan Alamina (2014), and Odiri (2015) about study habits. The reason for the non-significance maybe the difficulty in understanding mathematics lessons for some students. Although they possess an internal locus of control and desirable study habits, there is still a possibility to fail in the subject. The three domains of study habits in terms of reading ability, memory and health which are undesirable study habits of the students may also be the reason of the non-significant relationship.

Taken altogether, these three predictors may also affect mathematics achievement. The researcher is interested in finding a model that would best describe a students' mathematics achievement in terms of the predictors used. Multiple linear regressions were used in running the test. However, three iteration processes were done to obtain the desired results. Variables that are not predictors of mathematics achievement were removed for each process. Then, the test was used repeatedly to determine the most significant variable. Final results are presented in Table 3.

Table 3 shows that the regression equation model with unstandardized beta value is $Y=0.0622 X_{1}+9.6017$, where $Y$ as the dependent variable is the mathematics achievement and $X_{1}$ as the independent variable is the score in achievement motivation. For instance, if a student's score value in achievement motivation is 83 , the expected mathematics achievement is 14.7643.

The result revealed that for the predictor of mathematics achievement, it can be seen that only achievement motivation contributed positively to the students' mathematics achievement as evident in the beta coefficients of $0.0622(p$-value $=0.05)$. This further means that for every unit increase in the mathematics achievement is due to 0.0622 unit change of achievement motivation. 
The result also indicates that highly motivated students achieve higher in mathematics achievement. This conforms to the statement of Daniel (2015) that the more the students are motivated, the higher is their mathematics achievement. Hence, mathematics achievement could further be improved if students are academically motivated.

\section{DISCUSSIONS}

The study explored the predictive power of student's achievement motivation, locus of control and study habits towards their mathematics achievement. The findings of the study show several points of discussion.

Achievement motivation is an inner drive that motivates the students to achieve a particular goal. With average achievement motivation, a little guidance from the teacher is expected to achieve and perform better in mathematics. For most students, they believed that their present course will help them to be successful in the future. In addition, to do better is working harder, setting aside activities other than studying harder. These are proof of the positive relation between achievement motivation and academic achievement. This further implies that if a student is motivated in reaching goals in life, he/she can achieve more success as he/she will do everything to reach this goal.

Locus of control is a personal belief about who can control the consequences of a student's action, referring to success and failure in academics. Students having internal locus of control are expected to perform better in their academics given adequate feedbacks. However, given that internal locus dominates their characteristics as college students, they enrolled in college because they were expected to do so. Although they would like to finish college, it was not a mere priority for them but some other matters in their lives. This further explains the result of this study that having internal locus of control has nothing to do with the student's mathematics achievement. Success in mathematics can never be attributed to chance nor luck, neither ability nor effort, but is something is beyond having internal or external locus.

For students' study habits, the obtained desirable study habits were measured in terms of the eight domains of time management, physical status, study aids/note taking, testing strategies, learning motivation, reading ability memory and health. However, in terms of each domain, only the reading ability, memory and health gained undesirable study habits. This indicates that students did not manifest fondness in reading or may have difficulties in understanding the meaning of some words. Students also found it hard to remember the reviewed materials and experienced disappointments in the outcome of the examination. This may be indicative of some intervention activities that the teacher may use to improve study habits in terms of reading ability, memory and health as this have been to be influential in improved mathematics performance.

\section{CONCLUSIONS}

Majority of the first year students have average achievement motivation, internal locus of control and desirable study habits. This indicates that these students have moderate motivation to achieve success and that they perceive their success or failure through their own efforts and abilities in studying mathematics. When a student passes or fails in the subject, he or she takes full responsibility of the outcomes of his or her examination. A desirable study habits means that the student knows the importance of study habits in his or her mathematics achievement. In terms of mathematics achievement, most students are average achievers while only few students are found to be high and low achievers.

Significant relationship existed between achievement motivation and mathematics achievement. Moreover, achievement motivation was found to be the sole predictor of mathematics achievement. It can be stated that achievement motivation is effective in enhancing mathematics achievement. The students' motivation to achieve success will increase to high level if given the right remediation so as to attain high mathematics achievement. Thus, it can be concluded that a high achievement motivation can predict high mathematics achievement.

Author contributions: All authors have sufficiently contributed to the study, and agreed with the results and conclusions.

Funding: No funding source is reported for this study.

Declaration of interest: No conflict of interest is declared by authors.

\section{REFERENCES}

Anakwe, A. (2018). Adolescents and academic achievement in Nigeria today. International Journal of Education and Research, 6(1), 69-76.

Andaya, O. J. F. (2014). Factors that affect mathematics achievements of students of Philippine Normal University - Isabela Campus. International Refereed Research Journal, 5(4), 83-90.

Arora, R. (2016). Academic Achievement of Adolescents in Relation to Study Habits. The International Journal of Indian Psychology, 3(2), 47-54. https://doi.org/10.25215/0302.159

Atetwe, A. T., Aloka, J. P, \& Gudo, C. O. (2018). Influence of internal locus of control on mathematics achievement among students in secondary schools in Kenya. International Journal of Education and Research, 6(8), 153-162. 
Charles-Ogan, L. G., \& Alamina, J. (2014). Student's study habit and performance in public and private secondary schools mathematics in Port Harcourt Local Government Area, Rivers State. Journal of International Academic Research for Multidisciplinary, 2(7), 258-265.

Chetri, S. (2014). Achievement motivation of adolescents and its relationship with academic achievement. International Journal of Humanities and Social Science Invention, 3(6), 8-15.

Choudhury, S. A., \& Borooah, I. P. (2017). Locus of control and academic achievement of undergraduate college students of Guwahati City. International Journal of Humanities and Social Science Invention, 6(4), 67-70.

Curtis, N. A., \& Trice, D. (2013). A revision of the academic locus of control scale for college students. Perceptual \& Motor Skills: Physical Development \& Measurement, 116(3), 817-829. https://doi.org/10.2466/08.03.PMS.116.3.817-829

Daniel, A. (2015). Influence of achievement motivation and study habits on students academic achievement in mathematics. Indian Journal of Applied Research, 5(8), 562-565.

Dela Cruz, T. (2018). Study habits of ISPSC laboratory high school students its relation to their mathematics achievement. International Journal of Educational Science and Research, 8(2), 101-108. https://doi.org/10.24247/ijesrapr201815

Fini, A. A. S., \& Yousefzadeh, M. (2011). Survey on relationship of achievement motivation, locus of control and academic achievement in high school students of Bandar Abbas (Iran). Procedia-Behavioral Sciences, 30, 866-870. https://doi.org/10.1016/j.sbspro.2011.10.168

Gujjar, A., \& Aijaz, R. (2014). A study to investigate the relationship between locus of control and academic achievement of students. I-manager's Journal on Educational Psychology, 8(1), 1-9. https://doi.org/10.26634/jpsy.8.1.2763

Hasan, M., \& Sarkar, R. (2018). Achievement motivation and academic chievement of the secondary level students in Uttar Dinajpur District. Research Review International Journal of Multidisciplinary, 3(10), 249-252.

Kaur, J. (2017). Academic achievement of adolescents in relation to achievement motivation and study habits. International Research Journal of Multidisciplinary Studies, 3(9), 1-8.

Kaur, S. (2013). Academic achievement in relation to achievement motivation of high school students. International Journal of Science and Research (IJSR), 2(12), 409-411.

Khir, A. M., Redzuan, M., Hamsan, H. H., \& Shahrimin, M. I. (2015). Locus of control and academic achievement among Orang Asli students in Malaysia. 2nd International Conference on Language, Education, Humanities an Innovation (pp. 84-90).

Kumar, J., \& Asha, M. (2017). A study of relationship between academic achievement and locus of control of male and female senior secondary school students. Scholarly Research Journal for Humanity Science and English Language, 4(21), 4979-4986.

Kushwaha, S. S. (2014). Trend in researches on mathematics achievement. Journal of Research and Method in Education, 4(6), 5362. https://doi.org/10.9790/7388-04625362

Lawrence, A. S. (2014). Relationship between study habits and academic achievement of higher secondary school students. Indian Journal of Applied Research, 4(6), 143-145. https://doi.org/10.15373/2249555X/June2014/43

Mashayekhi, F., Mashayekhi, A., Faramarzpoor, M., \& Rafati, S. (2014). Key learning issues: Relationship between locus of control and study habits with academic achievement. Biomedical and Pharmacology Journal, 7(2), 567-573. https://doi.org/10.13005/bpj/525

Mashayekhi, F., Rafati, S., Mashayekhi, M., Rafati, F., Mohamadisardoo, M. R., \& Yahghi, E. (2014). The relationship between the study habits and the academic achievement of students in Islamic Azad University of Jiroft Branch. International Journal of Current Research and Academic Review, 2(6), 182-187.

Mathur, R. (2014). Academic achievement of college students and their locus of control. The International Journal of Indian Psychology, 1(3), 78-83. https://doi.org/10.25215/0103.008

Mulder, P. (2015). McClelland motivation theory. https://www.toolshero.com/psychology/theories-of-motivation/mcclellandmotivation-theory/

Nongtdu, S., \& Bhutia, Y. (2017). Locus of control in relation to academic achievement of college students in Meghalaya. 4th International Conference on Multidisciplinary Research \& Practice (pp. 159-165).

Obiero, J. (2017). The relationship between achievement motivation and mathematic performance amongst female learners and in selected urban girls' secondary schools in Kenya. Global Journal of Social Sciences Studies, 4(1), 23-29. https://doi.org/10.20448/807.4.1.23.29

Odiri, O. E. (2015). Relationship of study habits with mathematics achievement. Journal of Education and Practice, 6(10), 168-170.

Patena, A., \& Dinglasan, B. (2013). Students' performance on mathematics departmental examination: Basis for math intervention program Asian academic research. Journal of Social Science \& Humanities, 1(14), $255-268$. https://doi.org/10.2139/ssrn.2276044

Raheem, I. A., \& Abdulkadir, A. O. (2018). Predictive value of locus of control on academic performance of senior secondary school students in Sokoto Metropolis, Sokoto, Nigeria. International Journal of Humanities and Social Science Invention (IJHSSI), 7(1), 16-20.

Rani, P., \& Reddy, G. (2019). A study on achievement motivation of adolescent students of different academic streams. International Journal of Current Microbiology and Applied Sciences, 8(2), 228-233. https://doi.org/10.20546/ijcmas.2019.802.028 
Roy, A. G. (2015). A correlational study of achievement motivation and academic achievement of the elementary school students. International Journal of Innovation and Research in Educational Sciences, 2(3), 233-235.

Sahayarani, J., \& Stanley, S. L. (2017). Influence of achievement motivation on achievement in mathematics of ix standard boys and girls. Indian Journal of Research, 6(6), 525-526.

Sarangi, C. (2015). Achievement motivation of the high school students: A case study among different communities of Goalpara District of Assam. Journal of Education and Practice, 6(19), 140-144.

Sharma, G., \& Vyas, C. (2016). A review on study habits of school going children in relation to their academic achievement. International Journal of Scientific Research in Science and Technology, 2(5), 166-171.

Singh, P. (2015). Academic achievement in mathematics in relation to study habits. International Journal of Innovative Research and Development, 4(5), 302-306.

Suresh, K. (2015). A study on study habits, achievement motivation and academic achievement of high school students. International Journal of Economic and Business Review, 3(10), 138-141.

Verma, A. (2016). A study of academic achievement among high school students in relation to their study habits. International Journal of Research in Humanities, Arts and Literature, 4(3), 75-88.

Why Do We Study mathematics? By Bill Owen. www.onlinelearningtips.com/2012/07/why-do-we-study-mathematics/

Yazdani, K., \& Godbole, V. S. (2014). Studying the role of habits and achievement motivation in improving student's academic performance. European Online of Natural and Social Sciences, 3(4), 827-839. 


\section{MATHEMATICS ACHIEVEMENT MOTIVATION SCALE}

\section{Modified and Adapted from Pratibha Deo and Asha Mohan's Achievement Motivation Scale as of December 2018}

DIRECTIONS: This is a scale to measure your achievement motivation. There is no right or wrong answer. There is no timelimit for completing this work, but try to work quickly and carefully and try to give the first and best responses that comes to your mind on reading each statement. Read each statement of an item very carefully and put a check on the space corresponding to the number or category which, in your opinion, best expresses your feelings using the following scale:

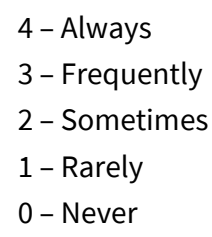

\section{Item \# Statements}

1. I shall be most pleased if I have to miss the mathematics classes for some days.

2. I pay full attention to the work in my mathematics class.

3. I mind much if I am late in my mathematics class.

4. I love to read a lot to find mathematics concepts and ideas.

5. I love to have a personal library and not just counting textbooks.

6. I set standards for myself and then strive to achieve them.

7. I wish to specialize and succeed in mathematics field.

8. I like to experiment and create new things and surprise people.

9 . I work hard for long hours to be successful in whatever I undertake.

10. I have a tendency to find solutions to any problems.

11. I aspire to get excellent results in mathematics.

12. I am ready to leave a task half done and try a new one.

13. I get nervous in the examination if one or two questions are not from the syllabus.

14. I prefer to go to a party rather than prepare for a mathematics examination next week.

15. When I get low marks in mathematics, I feel disappointed and determine to work hard to do better next time.

16. I think I find my lessons in mathematics meaningful and interesting.

17. While studying in mathematics, my mind wonders of the lesson and I get lost in imagination.

18. I think it is better to gossip away in the canteen than to attend mathematics classes.

19. When my mathematics teacher is teaching, I like to read stories/novels/comics or make cartoons in the class.

20. The university haunts me and I want to leave it at the very first opportunity.

21. It irritates me a lot if I have to stay late in the university for some mathematics lectures.

22. I want to go to the university because there are plenty of opportunities to enjoy life.

23. I think studies, sports and other activities can go together.

24. I lagree that the present course of my study will help me to be successful in the future.

25. I feel very much frustrated if I do not get a chance to compete in the field of my choice.

26. I regularly take down notes in the mathematics class and complete my assignments.

27. I plan to study carefully all year round in an effort to get good marks in mathematics.

28. I believe in studying first then play later.

29. I do a lot of preparation at home for the next day's work in my mathematics class.

30. I like to ask questions regarding every information given in tables and charts in the mathematics books rather than leave them as such and read further.

31. I think my mathematics teachers are competent with their work.

32. I like to create nuisance in my mathematics class and annoy the teacher.

33. I try my utmost to please my mathematics teacher through work and not through flattery.

34. My friends consider me dull and shirker.

35. It is true that my mathematics teacher think of me as a sincere and hardworking student.

36. I am hurt if others (parents, teachers and friends) criticize me but I try to improve upon my weaknesses.

37. My parents advise me to take life easy and never bother too much for my studies.

38. I wish to carry my mission forward in spite of facing a lot of criticisms.

39. I think my life is intellectually challenging.

40. I am interested in organizing the activities of a group team/class/committee.

41. I try to get associated with top most persons in the field of my choice.

42. I love to have some adventure in my leisure hour. 


\section{LOCUS OF CONTROL SCALE}

\section{Modified and Adapted from Ashton D. Trice's Academic Locus of Control Scale as of December 2018}

Directions: Answer each question below with a T for "true" and F for "false". Write your answer on the space provided before each number.

1. I came to college because it was expected of me.

2. I have largely determined my own career goals.

3. Some people have a knack for problem solving, while others will never solve problem no matter how hard they tried.

4. mathematics is a subject in which I could never do well.

5. I sometimes feel that there is nothing I can do to improve my situation.

6. I never feel really hopeless - there is always something I can do to improve my situation.

7. I would never allow social activities to affect my studies.

8. Studying every day is important.

9. It is not important to go to mathematics class.

10. I consider myself highly motivated to achieve success in life.

11. I am good in problem solving.

12. Doing work on time is always important to me.

13. I am easily distracted.

14. I can be easily talked out of studying.

15. I get depressed sometimes and then there is no way I can accomplish what I know I should be doing.

16. Things will probably go wrong for me some time in the near future.

17. I keep changing my mind about my goals.

18. I feel I will someday make a real contribution to the world if I work hard at it.

19. There has been at least one instance in school where social activity impaired my academic performance.

20. I would like to graduate from college, but there are more important things in my life.

21. I plan well and I stick to my plans. 


\section{MATHEMATICS STUDY HABITS INVENTORY}

\section{Modified and Adapted from Palsane and Sharma's Study Habits Inventory as of December 2018}

INSTRUCTIONS: Much of your success in the examinations depends upon the way you study your mathematics subjects. Following are the statements describing your habits of study. We wish to know your study habits so that we may help you in getting better marks in your examination. Your active cooperation, therefore, is absolutely needed.

Please read the following statements. There is no time limit, but give answers to all the statements as honest and as careful as possible.

Three alternatives are given for your answers (2) Always or Mostly, (1) Sometimes, and (0) Rarely or Never. Kindly encircle the number as it applies to you using the following scale:
2- (Always or Mostly)
1- (Sometimes)
0 - (Rarely or Never)

\section{Statements}

1. I study mathematics every day.

2. I study mathematics at a particular time of the day.

3. I do my homework in mathematics daily.

4. If I have to study in mathematics for a longer time, I take rest in between.

5 . I have all the required books and other relevant materials of study with me.

6 . I easily get disturbed by the surroundings at the time of the study.

7. I develop an automatic interest in the lessons in mathematics as soon I start studying it.

8. I realized the importance of mathematics for my future career.

9. Other stray thoughts gradually flow in, as soon as I settle down for the study.

10. I try to recall the matter after reading it.

11 . I continue my reading despite the difficulties in understanding meaning of some of the Mathematical languages.

12. I study figures and graphs very carefully while reading.

13. During the classroom teaching in mathematics, I take down notes very sincerely.

14. At home, I compare my class notes with the notes from the textbooks in mathematics.

15. I take help of anybody, if I do not follow anything.

16. I study the lesson in mathematics at home thoroughly before it is taught in the classroom.

17. I attend my mathematics classes regularly on time.

18. I frequently remain absent from my mathematics class.

19. I crammed certain things without understanding.

20. I study in the library regularly.

21. During examination days, I sleep as usual at night.

22. Before writing the answers to the questions in the mathematics examination. I read very carefully the entire question in the test paper.

23. In my mathematics examination, I answer the question in their serial order.

24. I divide the time according to the matter to be answered with respect to the number of questions.

25. Before my mathematics examination, I read my own notes carefully.

26. I prepare for the examination in mathematics from the guides/notes available in the market.

27. I draw an outline of answers for each question before writing the answers to the questions in the examination.

28. I feel tense at the beginning of the examination.

29. After the examination, I realized that I have made some mistakes in the answers I have

Always or Sometim Rarely or Mostly es Never

$\begin{array}{llc}\mathbf{2} & \mathbf{1} & \mathbf{0} \\ 2 & 1 & 0\end{array}$

2

2

2

1

1

2

0

0

$2 \quad 110$

2

2

2

1

1

1

1

1

0

0

1

0
written or I have forgotten some important points.

30 . I carefully record my examination result in mathematics.

31 . I single out the difficult topic on the strength of my examination results.

32. I try to make up for my deficiencies in mathematics.

33. I get disappointed if the examination result in mathematics is not favourable.

34. I have a tendency to compare my marks in mathematics with others after the results are declared.

35. I think that I can improve fairly my study habits in mathematics.

36. I get guidance about proper study habit from my mathematics teachers.

37 . I will take advantage if a guidance program on study habits is arranged.

\begin{tabular}{lll}
2 & 1 & 0 \\
\hline 2 & 1 & 0 \\
\hline 2 & 1 & 0 \\
\hline 2 & 1 & 0 \\
\hline 2 & 1 & 0 \\
\hline 2 & 1 & 0 \\
\hline 2 & 1 & 0 \\
\hline 2 & 1 & 0 \\
\hline 2 & 1 & 0 \\
\hline 2 & 1 & 0 \\
\hline & 1 & 0
\end{tabular}

$\begin{array}{lll}2 & 1 & 0 \\ 2 & 1 & 0\end{array}$

\begin{tabular}{lll}
2 & 1 & 0 \\
2 & 1 & 0 \\
\hline 2 & 1 & 0
\end{tabular}

$\begin{array}{lll}2 & 1 & 0 \\ 2 & 1 & 0\end{array}$

\begin{tabular}{lll} 
& & \\
2 & 1 & 0 \\
2 & 1 & 0 \\
2 & 1 & 0 \\
\hline 2 & 1 & 0 \\
\hline 2 & 1 & 0
\end{tabular}




\section{MATHEMATICS ACHIEVEMENT TEST}

Direction: Answer the following to the best of your knowledge. On the answer sheet provided, write the letter that corresponds to the correct answer.

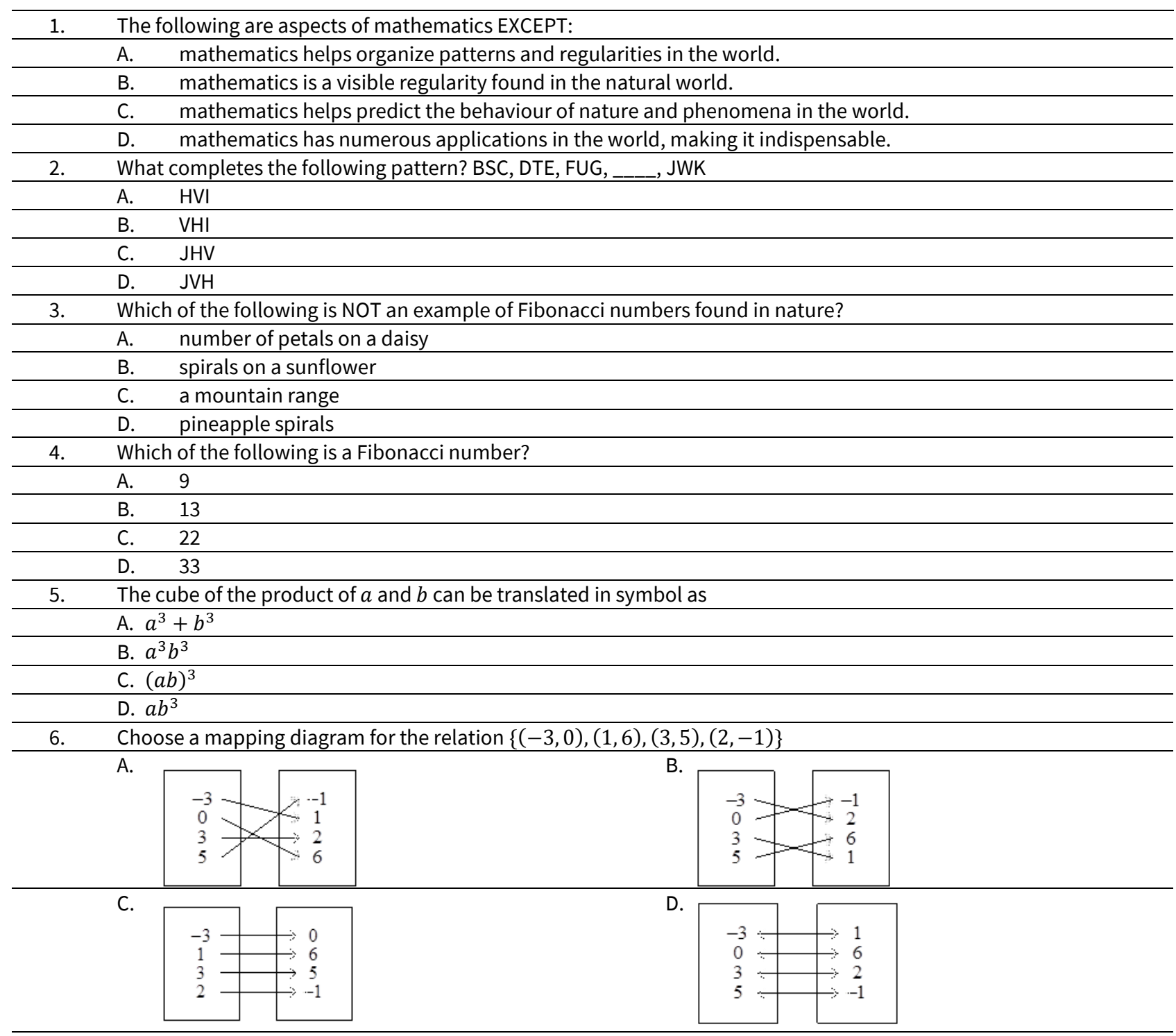

\begin{tabular}{ll}
\hline 7. & The set $F=\{0\}$ is an example of: \\
\hline A. & finite set \\
\hline B. & infinite set \\
\hline C. & empty set \\
\hline D. & universal set \\
\hline
\end{tabular}

8. Which of the following is a monomial?

Which of the following is a monomial?
A. $\frac{1}{x}$
B. $\sqrt{x}$
C. $x^{2} y^{4}$
D. $x+1$
The following is an example of an open sentence EXCEPT:
A. $2 x y<3 y$
B. $x+y=4$
C. $a b c=4$
D. $2(x+y)=2 x+2 y$


10. Which graph represents a function?

A.

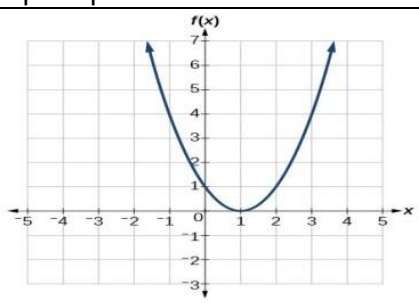

B.

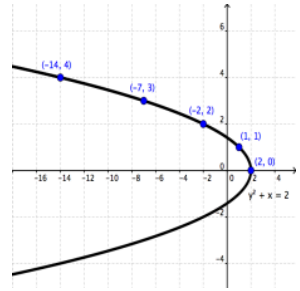

C.

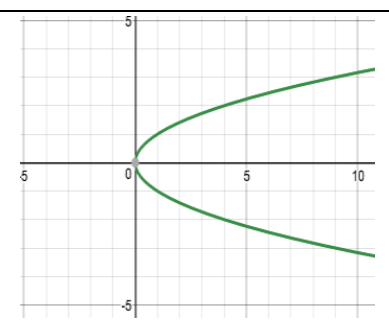

D.

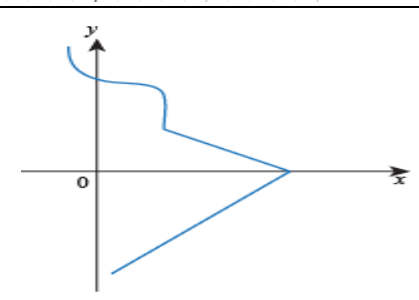

11. Let $M=\{0,2,4,6,8,10\}$ and let $N=\{x \mid x$ is an even number less than 10$\}$. Which of the following statements is true?

A. $M=N$

B. $\quad M \neq N$

C. $M>N$

D. $\quad M<N$

12. Which of the following functions is NOT one-to-one?

A. $\quad\{(1,2),(2,3),(3,4),(4,5)\}$

B. $\quad\{(1,2),(2,1),(3,4),(4,3)\}$

C. $\{(1,1),(2,2)(3,3),(4,4)\}$

D. $\quad\{(1,2),(2,1),(3,1),(4,3)\}$

13. A number $x$ is subtracted from two times its square and the result is 45 . An equation to find the value of $x$ would be:
A. $2 x-x^{2}=45$
B. $x^{2}-2 x=45$
C. $2 x^{2}-x=45$
D. $2 x^{2}-2 x=45$

14. Out of 35 students, 20 have at least one brother and 18 have at least one sister. Eleven students have both brothers and sisters. How many students do not have either a brother or a sister?

\begin{tabular}{ll}
\hline A. & 11 \\
\hline B. & 9 \\
\hline C. & 8 \\
\hline & D. $\quad 7$ \\
\hline $15 . \quad$ Let $f(x)=2 x^{2}-2$ and $g(x)=-x^{2}+5$. Find $(f+g)(-2)$. \\
\hline & A. 7 \\
\hline B. & 8 \\
\hline C. & -2 \\
\hline D. & 16
\end{tabular}

16. Which equation best describes the relationship between the corresponding values of $x$ and $y$ shown in the table?

$\begin{array}{cc}\boldsymbol{x} & \boldsymbol{y} \\ 2 & -6 \\ 1 & -8 \\ 0 & -10 \\ -1 & -12\end{array}$

A. $y=x-12$

B. $y=2 x-10$

C. $y=x^{2}-10$

D. $y=x-8$ 
17. What is the process of making generalized decisions after observing repeated specific instances of phenomenon?

\begin{tabular}{cl}
\hline A. & Inductive reasoning \\
\hline B. & Deductive reasoning \\
\hline C. & Mathematical reasoning \\
\hline D. & Problem solving
\end{tabular}

18. Which step of Polya's process consists of identifying all relevant and irrelevant information in a problem?

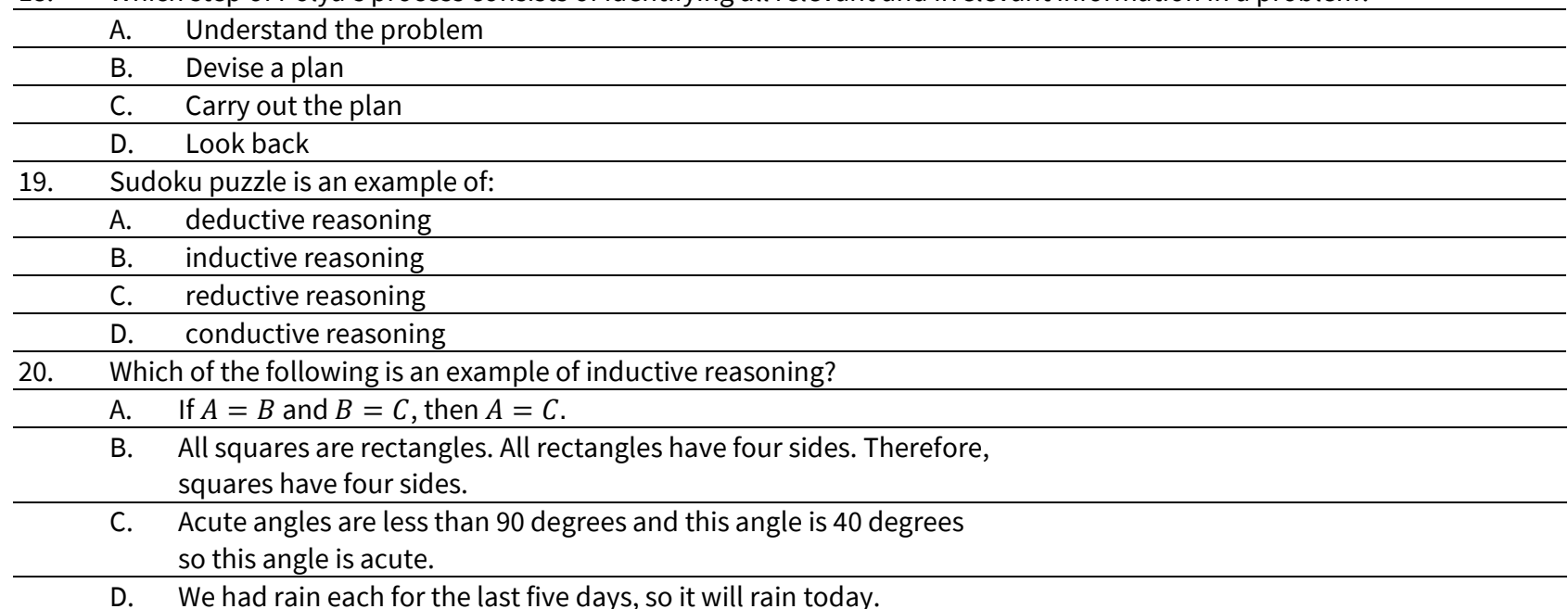

21. There are cows and chickens in a farm. The caretaker counted that there are 45 heads and 130 legs? How many cows are there?

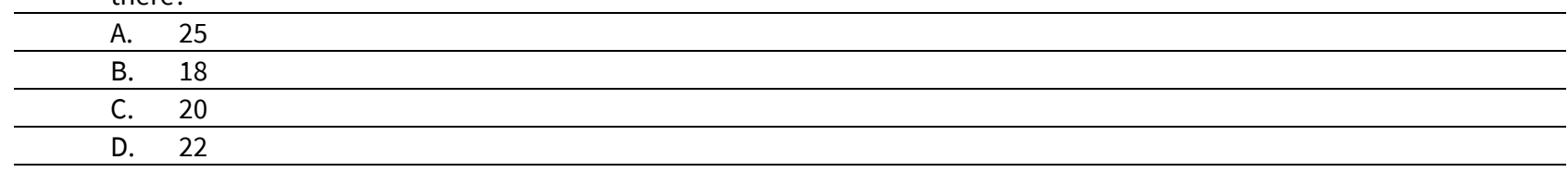

22. At the basketball game, Rommel was sitting in seat 143. Jevin was sitting to the right of Rommel in seat 144 . In the seat to the left of Rommel was Sheryl. April was sitting to the left of Sheryl. Which seat was April sitting in?
A. 141
B. 144
C. 145
D. 146

23. There are 364 Grade-one students in Park Elementary School. If there are 26 more girls than boys, how many girls are there?

\begin{tabular}{cr}
\hline A. & 169 \\
\hline B. & 195 \\
C. & 338 \\
D. & 390
\end{tabular}

24. In statistical analysis, the term array applies to which of the following?
A. Arranging the scores in rows and columns
B. Arranging the scores in an even or an odd set
C. Arranging the scores from lowest to highest or highest to lowest

25. The number of tally sheet count for each value or a group is called

\begin{tabular}{cl}
\hline A. & class limit \\
\hline B. & class frequency \\
C. & class size \\
\hline D. & class boundary
\end{tabular}

26. The class size for the class interval $36-45$ is

\begin{tabular}{ll}
\hline A. & 9 \\
\hline B. & 10 \\
\hline C. & 11 \\
\hline D. & 81
\end{tabular}

27. The sum of the deviations of the observations from the mean is

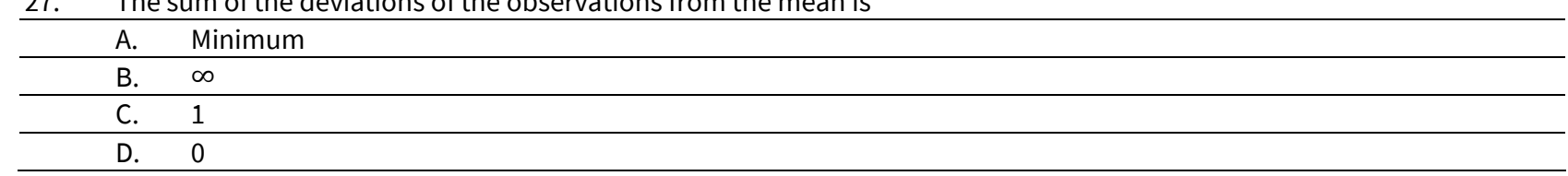


28. The lower and upper class limits are 32 and 40 , what is the midpoint of the class?
A. 8
B. 32
C. 36
D. 40

29. Which of the following represents an interval level of measurement?

A. main source of income

B. salaries of top managers in Cavite

C. military ranks

D. temperature inside 10 refrigerators

30. Which of the following is a discrete quantitative variable?

A. The weight of some students in a class

B. The time it takes to travel from home to school

C. The scores of various basketball teams

D. The amount of water consumed per day

31. All of the following are methods of data gathering EXCEPT:

A. direct method

B. questionnaire method

C. observation method

D. tabular method

32. The table below presents the average weight of 50 randomly selected male college students of Cavite State University General Trias City Campus.

$\begin{array}{cc}\text { Weight (in lbs.) } & \text { No. of Students } \\ 110-116 & 7 \\ 117-123 & 9 \\ 124-130 & 14 \\ 131-137 & 8 \\ 138-144 & 12\end{array}$

What is the relative frequency of the class interval $124-130$ ?

A. 14

B. 18

C. 28

D. 16

33. Given the frequency table in item no. 32, how many pieces of data were less than $131 \mathrm{lbs}$.?

A. 30

B. 14

C. 16

D. 20

34. Which of the following is true for the data set? $30,45,25,20,45$

A. Mean, mode and median are equal.

B. Mean is greater than the median and the mode.

C. Mean $=33$, Median $=30$, Mode $=45$

D. Mode is less than the mean and the median.

35. The mode score of the students on Statistics test was 95. Which of the following is true?

A. 95 is the highest score in the class

B. No one scored 95

C. More students received a 95 than any other score

D. 95 was slightly below average

36. If the average IQ of 10 students in mathematics is 112. If 9 students have scores of $118,116,104,125,103,115,109,99$ and 108. What must be the IQ of the other student?

\begin{tabular}{rr}
\hline A. & 112 \\
B. & 118 \\
C. & 120 \\
D. & 123
\end{tabular}


37. Given the following grouped frequency table, in which interval does the median fall?

$\begin{array}{cc}\text { Class Interval } & \text { Frequen } \\ 10-19 & 2 \\ 20-29 & 4 \\ 30-39 & 10 \\ 40-49 & 12 \\ 50-59 & 8\end{array}$

A. $10-19$

B. $20-29$

C. $30-39$

D. $40-49$

38. A student's grade point average (GPA) is calculated as a weighted mean, where the student's grade in each subject is given a weight equal to the number of units that subject is worth. Find Mark's GPA for the first semester.

Subject

Purposive Communication mathematics in the Modern World

Readings in Philippine History

Understanding the Self

The Contemporary World
Units

3

3

3

3

3
Grade

2.00

2.00

1.75

2.00

2.00

A. 15

B. 1.95

C. 2.00

D. 29.25

39. Which of the following does not need to be done when constructing a frequency distribution?

A. finding the difference between highest and lowest score

B. selecting the number of classes

C. using classes that are not mutually exclusive

D. using classes that are mutually exclusive

40. Which of the following pairs of class limits would be appropriate for grouping the numbers $12,15,10$ and 17 ?

A. $\quad 10-12$ and $13-17$

B. $10-13$ and $14-17$

C. $10-12$ and $15-17$

D. $9-13$ and $13-17$ 